\title{
Escrita-corpo-experiência e literatura: que pode o escrever (na pesquisa) [em educação matemática]?
}

\section{Writing-body-Experience and literature: what can writing (in a [mathematics education] research)?}

\author{
Paola Amaris-Ruidiaz ${ }^{\mathrm{a}}$; Roger Miarka \\ a Departamento de Educação Matemática, Universidade Estadual Paulista, Rio Claro, Brasil - paolaamaris@ gmail.com. \\ b Departamento de Educação Matemática, Universidade Estadual Paulista, Rio Claro, Brasil - roger.miarka@ unesp.br.
}

\section{Palavras-chave:}

Filosofia da diferença.

Ficção. Potência.

Cartografia.

\section{Keywords:}

Philosophy of difference. Fiction. Power.

Cartography.
Resumo: Este artigo trata da escrita como potência criadora, como possibilidade que se abre a experimentar uma ação que envolve relações entre corpo e potência. Para isso, abordaram-se movimentos conceituais de uma pesquisa de doutorado por meio de uma escrita-experimentação. Pratica-se uma cartografia escrita junto à literatura, em que foi tecida uma narrativa de ficção, uma pequena história que ajudou a dar conta dos conceitos a serem trabalhados na pesquisa. Criou-se assim uma grafia do corpo que ajuda a problematizar um discurso de apropriações. Nesse sentido, assumiu-se uma escrita-corpo, escolhendo-se uma política de escritahíbrida, que desfolhou conceitos que se engendraram no "fazer(-se) pesquisa". Considera-se que a problematização aqui proposta possa auxiliar no caminho de muitos outros que consigam ser afetados por meio deste texto, para vislumbrar outro modo de fazer pesquisa, em que sejam as próprias palavras que possam dar força aos seus próprios instantes, e que o sujeito pesquisador se constitua ao escrever(-se).

\begin{abstract}
This article deals with the writing as creative power, as a possibility that is opened to the experience of an action that involves relations between body and power. For this, conceptual movements of a doctoral research were approached through a writing-experimentation. It is practiced a written cartography nigh literature, in which a fictional narrative was woven, a small story that helped to explain the concepts to be worked in the research. This created a body graphy that helps to problematize a discourse of appropriations. In this sense, a writing-body was assumed, choosing a policy of hybrid writing, which defoliated concepts that were engendered in researching and in creating a research her/him/self at researching and writing. The problematization proposed here has the power of helping many others who may be affected by this text, to envisage another way of doing research, in which the words can give force and power to their own moments, and that the researcher is constituted by writing (her/him/self).
\end{abstract}


“Yo, señora, lo he llevado en las alas de la fantasía hasta el borde mismo del horizonte" (CORTÁZAR, 2015, p. 241).

\title{
Lições para uma boa escrita
}

Tome uma página em branco e

\author{
ocupe-a com palavras e \\ habite-a com ideias e \\ produza territórios sagrados e \\ profane o sacro riscando tudo a ponto de a escrita se tornar \\ outra coisa e \\ para fazer graça, não se esqueça do ponto final. É a melhor \\ maneira de enganar o leitor inocente, que pode pensar que a \\ escrita termina ali.
}

\section{O que pode a escrita?}

A pergunta "o que pode a escrita?" traz um pronome interrogativo iniciado com um artigo definido seguido de um verbo de potência e de um substantivo. Assim tomada, diz de antemão de uma série de possibilidades que a escrita já possui e que estão à espera de uma revelação. Não é dessa escrita que queremos falar, mas de uma outra, daquela que fissura a escrita a ponto de ela já não ser ela mesma, mas uma outra coisa. Almejamos a invenção junto à escrita, ir para além de seus limites, torcê-la de uma maneira pela qual não esteja preparada. Queremos tomar a escrita como potência criadora, invenção e, para tanto, abandonamos qualquer tentativa de uma escrita múltipla da ordem do "o que" e do substantivo "escrita" para dar vazão a uma multiplicidade própria do "que" e do verbo junto a seu movimento. Nosso objetivo aqui é "estimular a invenção em vez da revelação. A criação em vez da descoberta. A fetichização em vez da desfetichização. A fabricação de 'coisas' em vez da des-reificação. A ‘arte' em vez da 'ciência’. O artifício em vez do genuíno. O artefato em vez do fato. O feito em vez do achado" (CORAZZA; TADEU, 2013, p. 10).

O texto que ora conformamos não vem para explicar, mas para afetar, para dar vazão a uma multidão que habita quem escreve. Escrever, aqui, trata de inventar mundos, experimentar com a escrita, fazer da escrita um acontecimento. Que pode o escrever?

\section{Como compor uma pesquisa?}

Como corpo!

Como Corpo-Escrita-Experiência! 
$\mathrm{Na}$ ordem da invenção, buscamos, neste artigo, abrir possibilidades para a questão Como dar passagem aos afetos da experiência de pesquisar no ato de escrever? Por meio da experimentação de uma escrita a partir das afetações de uma pesquisa que não assumisse como ponto de partida uma prisão linguística, nem uma distinção entre realidade e ficção. Com isso, nesse exercício de escrita, distanciamo-nos da busca por uma "explicação da pesquisa", almejando que a pesquisa "aconteça" para o leitor em meio a um plano de intensidades constituído pelo pesquisador, formado por linhas de intensidades que visam à produção e à problematização, "como potenciais intensificadores que, juntas em uma mesma composição [...] possam acoplar-se de modo a produzir problemáticas, conceitos, ações, etc." (GONDIM; MIARKA, 2017, p. 117).

Para isso, operamos com obras de autores que assumem a diferença como possibilidade, tais como Deleuze, Guattari e Foucault, as quais chamamos de operantes por não as tomarmos como referências legitimadoras de ideias, mas tão somente como possibilidade para uma composição que funciona se autor e leitor com ela puderem operar e não por coerência com uma literatura anterior. Aqui nossos movimentos não vão em linha reta nem visam defender uma bandeira. Nossos movimentos são assumidamente caóticos, buscando por efeitos criadores sem a ilusão do rastreio de causas específicas.

A materialidade que originou este ensaio é oriunda de uma pesquisa de doutorado ${ }^{1}$ tomada como uma pesquisa cartográfica, na medida em que uma pesquisadora colombiana buscou acompanhar processos de subjetivação de um grupo de professores de matemática brasileiros de uma escola do interior do estado de São Paulo. Em meio a esse processo, uma problematização da escrita se mostrou viva e necessária, produzindo o texto "Prólogo a cuatro manos", que assumimos como seção central deste artigo.

Em uma pesquisa cartográfica, exercitamos um exercício de estar à espreita no mundo, vibrando junto a ele e assumindo a tríade ético-estético-política.

\begin{abstract}
Em que ético é o rigor com que escutamos as diferenças que se fazem em nós e afirmamos o devir a partir dessas diferenças. As verdades que se criam com este tipo de rigor, assim como as regras que se adotou para criá-las, só têm valor enquanto conduzidas e exigidas pelas marcas. Estético porque esse não é o rigor do domínio de um campo já dado (campo de um saber), mas sim o da criação de um campo, criação que encarna as marcas no corpo do pensamento como numa obra de arte. Político porque este rigor é o de uma luta contra as forças em nós que obstruem as nascentes do devir. (ROLNIK, 1993, p. 245).
\end{abstract}

"Um homem, ou mesmo dois homens comparados um com o outro, não têm o mesmo poder de serem afetados: eles não são afetados pelas mesmas coisas, ou não são afetados pela mesma coisa da mesma maneira" (DELEUZE, 2017, p. 147). Podemos dizer que essas afetações também são composições corpóreas produzidas a partir de suas marcas “[...] à

\footnotetext{
${ }^{1}$ Essa pesquisa de doutorado, trata de discutir a potência do corpo junto a uma educadora matemática em uma escola, buscando por possibilidades de invenção, criação e resistência.
} 
medida que [foi] mergulhando na memória para buscar os fatos e reconstruir sua cronologia, [...uma...] outra espécie de memória, uma memória do invisível feita não de fatos mas de algo que [acabou] chamando de marcas" (ROLNIK, 1993, p. 241), que têm a potência de voltar a serem recordadas quando atraídas por ambientes onde encontram ressonância. Quando isto acontece cria-se uma espécie de desassossego e conexões que se atualizam, gerando um novo modo de sentir ou agir: "que venha encarnar este estado inédito que se fez em nós. E a cada vez que respondemos à exigência imposta por um destes estados, nos tornamos outros" (ROLNIK, 1993, p. 241). São essas composições que nos fazem perguntar pela potência do corpo.

Essa potência, que entendemos ser criadora, é a que nos faz produzir este texto, assumindo-o como escrita política "porque é conceito de um ato" (RANCIÈRE, 1995, p. 7). Nessa perspectiva, traz a possibilidade de abordá-la como ação que envolve relações entre corpo/potência/escrita. Nesse viés, muito nos auxilia Michel de Certeau (2008) quando aponta o caminhar pela cidade como uma forma de escrita na superfície urbana, ou seja, uma grafia do corpo. Assim nos lançamos à experimentação com uma cartografia, em que o escrever se dá no caminhar.

Cartografia vem do grego chartis (mapa) e graphein (escrita), sendo aqui tomada no sentido dado por Deleuze e Guattari em Mil Platôs, volume 1, em que o ato de "construir um mapa não é um decalque. [...] Se o mapa se opõe ao decalque é por estar inteiramente voltado para uma experimentação ancorada no real. O mapa não reproduz um inconsciente fechado sobre ele mesmo, ele o constrói” (1995, p. 21).

Por esse graphein abordamos movimentos conceituais, os fluxos da pesquisa por meio de uma escrita/experimentação com aquilo que afeta, produz e vibra. Buscamos praticar uma cartografia por meio da literatura, em que uma tessitura foi elaborada em uma narrativa de ficção, uma pequena história que nos ajudou a dar conta dos conceitos a serem trabalhados na pesquisa. Contribuiu a mobilizá-los e compreendê-los, tanto para a pesquisadora quanto para toda sua pesquisa. Foi a forma encontrada de expurgar os movimentos caminhados na superfície cartografada, como uma grafia do corpo, um discurso de apropriações.Nesse sentido e por ser um processo de subjetivação, assumimos uma escrita-corpo.

Uma escrita-corpo de uma colombiana junto a um grupo de professores, em que uma linguagem híbrida se mostrou mais natural, o que nos levou a uma política de escrita-híbrida, um texto polifônico, que não se trata nem de português, nem de espanhol, mas de uma outra escrita, um outro modo de escrita. De todo modo, “QQué importa quién habla?" (FOUCAULT, 1992), quando o objetivo é a vazão dos afetos? Criamos assim uma escrita que tenta desfolhar "uma política de escrita que se engendra no fazer(-se) pesquisa, no fazer(-se) 
escrita" (CLARETO; VEIGA, 2016, p. 34), acompanhada pela experiência sensível e que fossem as próprias palavras que dessem força para seu próprio instante.

Por esses instantes queremos que os leitores assumam o estranhamento como potência de criação - "Quando estranho a vida aí é que começa a vida" (LISPECTOR, 1994, p. 83) -, de modo que optamos por não seguir as normas vigentes da Associação Brasileira de Normas Técnicas. Consideramos que o fluxo de leitura é muito mais eficiente quando assumida sua velocidade, sem os freios da autoria forçada. Afinal, quem é o autor de uma colcha de retalhos formada por milhares de pequenos pedaços de panos dos países mais longínquos? Os textos assumidos de outros nos servem tão somente para uma composição, para dar velocidade. Sua autoria é uma questão de vaidade e sua demarcação, considerada aqui como uma concessão a certo modo de operar na academia, se dará na forma de trechos em itálico. E no caso de o estranhamento causar efeito à vida, sugerimos aos leitores que se lancem na aventura de buscá-los na literatura.

Já falamos demais.

Convidamo-lhe à travessia...

\section{Prólogo a cuatro manos}

Era uno de esos días donde no hay control por lo que se escribe. Ella no quería dejar escapar ninguna idea antes de que fuese tarde, al final es tanta la presión y la agitación de su respiración que hasta sus dedos lo sienten. Rompe su mate, su florero de cristal que algunas veces le habla. Sale a caminar con sus manos atadas en la espalda, con su mirada en el horizonte, perdida, necesitando respirar palabras. Aparece de la nada, como la coma evocada, un bar. Ella entra, pide una copa de vino y al instante siente que alguien la mira. Tres seres extraños sentados en la última mesa susurran. Uno de ellos la mira con una intensidad tan fuerte que no puede evitar buscarla para hacerla coincidir con la suya.

Ella, P., está tan devastada que no le interesa nada, está en una encrucijada, no sabe cómo comenzar la escrita en su tesis, o más bien, cómo plasmar esos sonidos para que lleguen a ser melódicos en otros oídos. Toma lentamente un sorbo de vino y anota en su cuadernito aquellos pensamientos que, por si acaso, pudieran salir volando. Ya está en el punto donde no entiende nada de Filosofía, ni de Cine y mucho menos de Literatura. Por ahora ya no quiere más libros, sabe que ha llegado la hora de escribir para plasmar todo lo que la tiene incómoda.

Desde el fondo, se le acerca uno de esos seres, con cigarro en mano, y le pregunta:

- Você quer se juntar a nós e tomar uma taça de vinho naquela mesa? - señala al fondo del bar. 
P. por un momento se asombra. No sabía quién era ese ser, pero igualmente aceptó su invitación. Le mostró el camino para que la siguiera y llegaron juntas a la mesa. Le ofrece un asiento, P. lo acepta sin ningún obstáculo.

- ¿Quién sos vos? - le pregunta Él a P.

- Soy P. Mucho gusto - responde.

- Imagino que debes ser alguien que le interesa a Clarice, si no, ahora no estarías sentada junto a nosotros ¿Cierto? - dirige su pregunta a Clarice, que asienta la cabeza en señal de estar en lo cierto.

— ¿Por qué ella y por qué no otra persona del bar? — vuelve a preguntarle.

- Interessou-me seu lápis e sua folha - responde Clarice.

- ¿Qué escribís ahí? - le pregunta Él de nuevo a P.

— Mis pensamientos, quizás mis reflexiones, un libro de vida tal vez - responde $\mathrm{P}$.

- Bitácora, yo le llamaría - comenta Él. - Aquí tengo la mía, siempre la llevo conmigo - se lo muestra y en la primera página aparece una frase que de reojos P. comienza a leer.

— ¿Puedes leerla en voz alta? - le dice Él.

P. respira profundo, toma una boconada de aire y comienza a leer pronunciando cada letra, coma, punto, como narrando un poema frente a un gran auditorio.

- Cuantas veces me pregunto si esto no es más que escritura, en un tiempo en que corremos al engaño entre ecuaciones infalibles y máquinas de conformismos. Pero preguntarse si sabremos encontrar el otro lado de la costumbre o si más vale dejarse llevar por su alegre cibernética, ¿no será otra vez literatura? Rebelión, conformismo, angustia, alimentos terrestres, todas las dicotomías: el Yin y el Yang, la contemplación o la Tatigkeit, avena arrollada o perdices faisandées, Lascaux o Mathieu, qué hamaca de palabras, qué dialéctica de bolsillo con tormentas en piyama y cataclismos de living room. El solo hecho de interrogarse sobre la posible elección vicia y enturbia lo elegible. Que sí, que no, que en ésta está... Parecería que una elección no puede ser dialéctica, que su planteo la empobrece, es decir la falsea, es decir la transforma en otra cosa. Entre el Yin y el Yang, ¿cuántos eones? Del sí al no, ¿cuántos quizá? Todo es escritura, es decir fábula. ¿Pero de qué nos sirve la verdad que tranquiliza al propietario honesto? Nuestra verdad posible tiene que ser invención, es decir escritura, literatura, pintura, escultura, agricultura, piscicultura, todas las turas de este mundo.

- ¡Capítulo 73 de Rayuela! - exclama P.

- ¿Me lees? - le pregunta Cortázar con una sonrisa un poco irónica.

- Imposible no hacerlo - le responde P. - Más una razón para creer en las palabras. 
- Eu também acredito nelas - comenta Clarice. - Eu me encarno nelas, eu escrevo como exercício de esboços antes de pintar. Vejo as palavras. Escrevo com o corpo todo, escrevo porque não me entendo.

-As palavras têm tanta força - interfiere con un acento medio extraño el tercer ser, que hasta ahora no se había pronunciado. - Por exemplo, se eu não falo com ninguém, deixo marcas, porque me qualifico como alguém que não quer abrir a boca, se falo, deixo-as também, porque toda palavra pronunciada permanece e pode reaparecer em qualquer momento.

- ¿Cómo te llamas? - pregunta P.

Obviamente no parecía del tipo que se presentaría solo con su nombre. Fue un poco inocente por parte de P. hacerle ese tipo de pregunta. Él por su parte, llevando su mano a la barbilla, comienza su presentación poética.

- O único herói capaz de decepar a cabeça da Medusa é Perseu, que voa com sandálias aladas; Perseu, que não volta jamais o olhar para a face da Górgona, mas apenas para a imagem que vê refletida em seu escudo de bronze. Eis que Perseu vem ao meu socorro até mesmo agora, quando já me sentia capturar pela mordaça de pedra - como acontece toda vez que tento uma evocação histórico-autobiográfica.

- Responde sua pergunta? - le dice.

— ¡ Dejáte de pavadas, Calvino! - le comenta Cortázar sonriendo.

- Me incomodo - dice P.

- Você não tem porque se incomodar conosco - le dice Calvino. - Ou mais bem, será que você está incomodada com alguma coisa? Por isso acho que Clarice aproximou-selhe.

- Puede que sí - le responde P. y continúa hablando. - No dejo un instante de pensar, estoy cargando mi Hypomnemata, esa es mi Bitácora, Cortázar, mi cuadernito de pensamientos, de frases que intentan huir, pero yo las detengo en sus hojas, y con eso consigo a veces no dejarlas volar. Entre esos pensamiento, me incomodan cosas: debo escribir una tesis pero estoy ante, debajo, o en medio de una lengua mayor a la mía, quizás no mayor, una lengua que debo oficializar ante la Academia - el Portugués - escribiendo en Español mi escrita se volverá más potente, así puedo expresar todo, tal cual lo siento y deviene. Y así la pregunta vuelve ¿En qué lengua escribir mi tesis? - Todos ríen a carcajadas.

- Creo que vos misma has dado la respuesta - le dice Cortázar en su tono irónico. A ver si entendí - continúa hablando. - Necesitas explicar a la academia del por qué escribes en español o en portugués. Creo que eso es lo menos problemático, si al final al escribir una tesis debes crear tu propia política de escrita, eso debe ser el rastro que conlleva el acto de escribir. 
- Existe un mundo académico que le gusta exigir explicaciones - le responde $\mathrm{P}$.

- Explicar, explicar, explicar - continúa Cortázar. - Lo que me revienta es la manía de las explicaciones. Muchas veces he pensado que si hubiera podido explicar lo fantástico nunca hubiera escrito ningún cuento fantástico. Esto no es una explicación, es mi política de escrita.

- Há quem acha que a palavra seja o meio de se atingir a substância última continúa Calvino. - Única absoluta; a palavra, mais do que representar essa substância, chega mesmo a identificar-se com ela: há a palavra que só conhece a si mesma, e nenhum outro conhecimento do mundo é possível. Há, no entanto, pessoas para quem o uso da palavra é uma incessante perseguição das coisas, uma aproximação, não de sua substância, mas de sua infinita variedade, um roçar de sua superfície multiforme e inexaurível. Por isso o justo emprego da linguagem é, para ele, aquele que permite o aproximar-se das (presentes ou ausentes) com discrição, atenção e cautela, respeitando o que as coisas (presentes ou ausentes) comunicam sem o recurso das palavras.

- Las palabras, el impulso - interviene Cortázar. - Por eso no es casual que hable siempre de sentimiento de lo fantástico: no es una idea, ni un concepto, es un sentimiento de apertura, esa sensación de percepción de intersticios en lo real, de otras modulaciones de la realidad y el cuento funciona entonces como catarsis. Creo haberme librado de algunas neurosis escribiendo algunos cuentos fantásticos. Por eso, les pregunto ¿Por qué se escribe? ¿Por qué escribo? ¿Qué me da fuerza para hacerlo? voy a leerles esto que escribí en mi Bitácora:

- No tengo ideas claras, ni siquiera tengo ideas. Hay jirones, impulsos, bloques, y todo busca una forma, entonces entra en juego el ritmo y yo escribo dentro de ese ritmo, escribo por él, movido por él y no por eso que llaman el pensamiento y que hace la prosa, literaria u otra. Hay primero una situación confusa, que sólo puede definirse en la palabra; de esa penumbra parto, y si lo que quiero decir (si lo que quiere decirse) tiene suficiente fuerza, inmediatamente se inicia el swing, un balanceo rítmico que me saca a la superficie, lo ilumina todo, conjuga esa materia confusa y el que la padece en una tercera instancia clara y como fatal: la frase, el párrafo, la página, el capítulo, el libro.... Escribir es dibujar mi mándala y a la vez recorrerlo, inventar una purificación purificándose.

- Yo en cambio - continúa P. - escribo porque llega una idea y te aplasta si no las plasmas en un papel, porque se siente en la sangre cada letra no dicha, cada letra que intenta ser silenciada por palabras de orden. Escribo esta tesis como resistencia a las imposibilidades que otros crean para encuadrar lo que se escribe, un acto que se funda en la creación. Escribo para mí, para ti y para todos. Es el deseo de volar con cada letra pronunciada, con cada silencio guardado. Escribo porque es parte de mí ser. 
— ¿Importa en qué lengua se escribe eso? - le pregunta Cortázar a P. después de su desahogo.

- No - le responde P. y continúa hablando. - Creo que las palabras son como la música, al final tú la sientes, así no sepas lo que dice.

- Esse é um exemplo que eu uso muito para dizer da minha sensação de escrever dice Clarice y continúa su intervención. - Vejo que nunca te disse como escuto música apoio de leve a mão na eletrola e a mão vibra espraiando ondas pelo corpo todo: assim ouço a eletricidade da vibração, substrato último no domínio da realidade, e o mundo treme nas minhas mãos. E eis que percebo que quero para mim o substrato vibrante da palavra repetida em canto gregoriano... E se tenho aqui que usar-te palavras, elas têm que fazer um sentido quase que só corpóreo, estou em luta com a vibração última. Para te dizer o meu substrato faço uma frase de palavras feitas apenas dos instantes-já. P., por isso lhe pergunto, como você pode traduzir na sua escrita um instante-já? Em qual língua?

- Não é isso o importante, acho - interviene Calvino. - Não serei tão drástico: creio que nossos mecanismos mentais elementares se repetem através de todas as culturas da história humana, desde os tempos do Paleolítico em que nossos ancestrais se davam à caça e à colheita. A palavra associa o traço visível à coisa invisível, à coisa ausente, à coisa desejada ou temida, como uma frágil passarela improvisada sobre o abismo.

- Creo que el lenguaje no es suficiente para abarcar el mundo - comenta P. - , es más, siempre existirán cosas que escapan, es ahí donde está su belleza. Cuando se toma el lenguaje para aproximar el objeto del cual que se habla, codificando y describiéndolo, creo que es ahí donde pierde la potencia, incluso hasta de la imaginación. Yo no quiero describir, ni explicar. Tampoco estoy en la búsqueda de un sentido delineado sobre transversalidades epistemológicas cayendo en indeterminaciones circulares.

— ¿Qué es lo que vos querés hacer en tu tesis entonces? - le pregunta Cortázar.

- Hay una frase de Kafka que siempre me deja pensando cada vez que la leo - le responde y continúa hablando - un escritor debería escribir siempre en una lengua extranjera. Por eso cuando escribo siento como si no fuera solo yo, sino todos los muchos que me habitan. Hago escritura de mis deseos. Una escritura que me atraviesa, una escritacuerpo. Escribir con el cuerpo es más allá de una palabra delineada, es escribir por medio de las afectaciones, de las profundidades que son más incoherentes que la propia realidad. Quiero una escrita rebelde, aquella que inquieta, que hace bailar. Somos seres discontinuos y el lenguaje fijo nos hace callar con sus códigos enmarcados para asegurar su propia subsistencia. La escritura es algo imprevisible, un abismo puede aparecer al final de una frase o al comienzo de una hoja en blanco. Esto ha sido una lucha diaria de cada escritor, un universo conquistado, no adquirido, ha sido luchado a través de los tiempos. Ahora, comprendiendo 
todo lo que dicen, creo que para mí, lo más importante es ¿Cómo producir una escrita potente? Mi propio desierto. ¿Cómo hacer vibrar el lenguaje con intensidad? "Como tornar-se o nômade e o emigrado e o cigano de sua própria língua?"

- Ahhh pero estás juntando dos lenguas en lo que dices, portugués y español ¿Y al final en que lenguas nos leíste a todos aquí? - pregunta Cortázar.

- Cortázar, a ti te leí en español, en nuestra lengua materna. A ti Calvino en español y portugués, que es la lengua más próxima que tengo ahora. Y a ti Clarice en portugués, claro está.

- Pero Calvino no escribía ni en español, ni en portugués - le dice Cortázar.- Él escribía en italiano. Al final todos somos errantes en la lengua. Por eso, creo que también es importante el contacto con el lector. En eso es en lo que debes pensar y sobre todo sentir. Porque, mirá, hay varias posibilidades:

La primera. Situación del lector. En general todo novelista espera de su lector que lo comprenda, participando de su propia experiencia, o que recoja un determinado mensaje y lo encarne. El novelista romántico - que creo que no es tu caso- quiere ser comprendido por sí mismo o a través de sus héroes, el novelista clásico quiere enseñar, dejar una huella en el camino de la historia. Otra posibilidad. Hacer del lector un cómplice, un camarada de camino. Simultaneizarlo, puesto que la lectura abolirá el tiempo de lector y lo trasladará al del autor.

— Esa me gusta - comenta P., sonriéndole. - Un cómplice de camino.

- Pero creo que antes de la relación con el lector - continúa Cortázar - hay que tener en cuenta el cómo se narra la historia. Por ejemplo, para mí es importante una narrativa que no sea pretexto para la trasmisión de un mensaje (no hay mensaje, hay mensajeros y eso es el mensaje, así como el amor es él que ama) una narrativa que actúe como coagulante de vivencias, como catalizadora de nociones confusas y mal entendidas, y que incida en primer término en él que la escribe, para la cual hay que escribirla como anti novela porque todo orden cerrado dejará sistemáticamente afuera esos anuncios que pueden volvernos mensajeros, acercarnos a nuestros propios límites de los que tan lejos estamos cara a cara.

- Sí, eso es lo que quiero - le comenta $\mathrm{P}$ y continúa hablando. - Tal vez renunciando al supuesto de que una narración es una obra de arte. Sentirla como sentiríamos el yeso que vertemos sobre un rostro para hacerle una mascarilla. Pero el rostro debería ser el nuestro.

- Exactamente eso deberías hacer - le responde Cortázar.

- ¿Y sabes quién dice eso? - le pregunta $\mathrm{P}$.

- No - le responde.

- ¡Vos! 
Todos en la mesa ríen desaforadamente, por la broma que le acaba de hacer P., pues las palabras también se olvidan. En ese momento le pregunta Calvino a P.

— ¿Cómo querés hacer todo eso? ¿La narrativa, la escritura, tu tesis? ¿A partir de qué?

- Yo te voy a responder con una situación que plantea Cortázar. Me disculpas de nuevo por usar tus palabras - le dice $\mathrm{P}$.

- Tranquila - le dice Cortázar.- Hace rato no me acuesto con las palabras, las sigo usando como vos y como todos. - Todos sonríen por el comentario.

- Capitulo 84 de Rayuela - P. vuelve a abrir su hypomnemata y comienza su lectura:

Vagando por el Quai de Célestins piso unas hojas secas y cuando levanto una y la miro bien la veo llena de polvo de oro viejo, con por debajo unas tierras profundas como el perfume musgoso que se me pega en la mano. Por todo eso traigo las hojas a mi pieza y las sujeto en la pantalla de una lámpara. Viene Ossip, se queda dos horas y ni siquiera mira la lámpara. Al otro día aparece Etienne, y todavía con la boina en la mano, Dis donc, c'est épatant, ça!, y levanta la lámpara, estudia las hojas, se entusiasma, Durero, las nervaduras, etcétera.

Una misma situación, dos versiones... me quedo pensando en todas las hojas que no veré yo, el juntador de hojas secas, en tanta cosa que habrá en el aire y que no ven estos ojos, pobres murciélagos de novelas y cines y flores disecadas. Por todos lados habrá lámparas, habrá hojas que no veré.

Eso es para mí investigar, habitar los espacios, los libros, la ciencia, incomodarse con lo que es habitual. Hay tantas cosas que no veré, hay otras tantas que sentiré. Cada extrañamiento puede generar un mundo, el mundo, es eso, las hojas; y ¿cómo hacer visible esos detalles? De eso depende nuestra sensibilidad. Hay que hacer vibrar nuestra atención en esos detalles, cada acción puede cambiar un mundo.

- O estranhamento, é isso o que me interessa - dice Clarice. - Eu nunca fui moderna. E acontece o seguinte: quando estranho uma pintura é aí que é pintura. E quando estranho a palavra aí é que ela alcança o sentido. E quando estranho a vida aí é que começa a vida. Tomo conta para não me ultrapassar. Há nisto tudo aqui grande contenção. Só não te contaria agora uma história porque no caso seria prostituição. E não escrevo para te agradar.

- Che, Clarice, vos no necesitás agradar a nadie, con solo verte ya eres todo un encanto - todos ríen con el comentario de Cortázar en la mesa. - Ahora sí, hablando serio, el extrañamiento es necesario, cuando se extraña el mundo, es cuando más nos ofrece algo. Es interesante lo que vos pensás Clarice y P., creo que son de las pocas personas que piensan que el mundo puede ser inalcanzable para el lenguaje, porque él es independiente de nosotros. 
- Sim, por isso prefiro as verdades inventadas - sonríe Clarice de su proprio comentario.

- Prefiero esas verdades a las verdades absolutas, ¿saben qué es un absoluto? - les pregunta Cortázar a todos y él mismo responde. - Viene a ser ese momento en que algo logra su máxima profundidad, su máximo alcance, su máximo sentido y deja por completo de ser interesante. Por eso, mi querida amiga P., jemborrachémonos de metáforas y analogías! Tenemos que pensar, lo que se llama pensar, es decir sentir, situarse y confrontarse antes de permitir el paso de la más pequeña oración principal o subordinada como ya dije antes "la acción puede servir para darle un sentido a tu vida”

- Por isso, é preciso ser leve como o pássaro, e não como a pluma - interviene Calvino. - Cada vez que o reino do humano me parece condenado ao peso, digo para mim mesmo que à maneira de Perseu eu devia voar para outro espaço. Não se trata absolutamente de fuga para o sonho ou o irracional. Quero dizer que preciso mudar de ponto de observação, que preciso considerar o mundo sob uma outra lógica, outros meios de conhecimento e controle. As imagens de leveza que busco não devem, em contato com a realidade presente ou futura, dissolve-se como sonhos...

- Calvino, Clarice, Cortázar, - dice P. - Creo que hay que tomar esto como un viaje, ahora lo digo en boca de cuatro: el pasado del viajero cambia según el itinerario cumplido, nuestro instante es el presente que ya fue. El problema de la realidad no se enfrenta con suspiros y la revolución puede ser un gran carnaval. Sé que el camino es largo, pero siempre habrá un punto de encuentro, como Oliveira y la Maga, Cortázar, que andaban sin buscarse pero sabiendo que andaban para encontrarse.

\section{Que pode o escrever (na pesquisa) [em educação matemática]?}

Uma página em branco, um vazio? Um lugar onde as potencialidades podem ser atravessadas, onde máscaras e rostos podem aparecer ou desaparecer no caminho do escrever. Salpicamos tinta negra sobre uma folha à espera de que de algum modo pudéssemos ser localizados por nossos leitores. Queremos, sim, ser localizados, mas não como sombras, não como fantasmas errantes. Queremos ser localizados pela lógica na onipresença, como um fluído que envolve o seu entorno, que habita as vísceras de seu leitor, fazendo-o expurgar seus próprios líquidos, sejam eles feitos de mel ou de fel.

Em meio a esse processo, assumimos nomes, mas nomes que em seu âmago são uma multiplicidade que não caberiam integralmente em nomes próprios. Cada nome é uma multidão e se um nome não define, então, lhes perguntamos por que deles precisamos para além da vaidade? 
Nomear [...]: dar um nome. Nome: vocábulo ou locução que tem a função de designar uma pessoa, um animal, uma coisa ou um grupo de pessoas, animais e coisas. Dentre os nomes que designam, há os nomes comuns e os nomes próprios. Comum, do latim communis. Uma acepção: Do uso ou domínio de todos os de um lugar ou de uma coletividade. Próprio, do latim proprius. Uma acepção: Que pertence exclusivamente a alguém. (CLARETO; MIARKA, 2015, p. 796).

Este texto não nos pertence, e não nos pertenceria ainda que fosse escrito na primeira pessoa. "Eu", como sujeito, pertence a quem se entregar à leitura. Este texto é tecnicamente escrito a quatro mãos, mas recordamos que estas mãos por si só já eram muitas outras e que cada uma delas deram mãos a outras personagens. Eis uma multidão que escreve.

\begin{abstract}
Sinto-me múltiplo. Sou como um quarto com inúmeros espelhos fantásticos que torcem para reflexões falsas uma única anterior realidade que não está em nenhuma e está em todas. [...] Sinto-me viver vidas alheias, em mim, incompletamente, como se o meu ser participasse de todos os homens, incompletamente de cada [?]. (PESSOA, 1974, p. 84).
\end{abstract}

E como somos múltiplos, assumimos ser vários também na escrita. Foucault (1996, p. 166) já nos alertou que "a visibilidade é uma armadilha", de modo que nos é um prazer sermos mascarados com nossas letras em meio a essa multidão.

A criação faz parte deste texto, não como movimento já constituído, mas pela possibilidade de um movimento constituidor, para provocar ações criadoras, com tinta, sangue e papel. "A escrita está liberta do ato da palavra" (RANCIÈRE, 1995, p. 8). E a palavra? Está liberta de nossos universais? Não queremos produzir verdades que sejam a luz do caminho das nossas pesquisas. Nós escrevemos com os afetos, aqueles que nos incomodam e produzimos este artigo para que nossa parrhésia ${ }^{2}$ nossa coragem de dizer o que nos afeta, seja quem produza a vontade própria de se mover, para que nem o céu seja um limite, para que esta escrita mobilize e deixe seu leitor levar-se pelo infinito, nesse "lugar donde los pollos se pasean crudo" (CORTÁZAR, 2017, p. 18).

Perder-se é encontrar-se e a cada vez que se pergunta a própria afetação poderá surgir. Eis a eterna possibilidade da singularidade. No entanto, se nos perguntamos pelo sentido, por esse que categoriza, vamos perdendo a magia de se deixar perder, porque estaremos procurando verdades que possam garantir que há uma estátua por trás da cortina. Ao final, não é o que está detrás dela, senão a própria cortina o que nos interessa.

Quando escrevemos a partir da experiência sensível suspeitamos de um vínculo entre a subjetividade daqueles que escrevem essas letras e seus próprios processos de afetação. Realidade e ficção perdem suas fronteiras e fica assim exposta a afirmação da vida como uma escrita singular. Dessa maneira, assumimos uma política de escrita vinculada ao processo de subjetivação, aos encontros, que caracteriza a possibilidade de que as pontes das línguas passem por nossas afetações, produzindo uma escrita-corpo com a intenção de estabelecer

\footnotetext{
${ }^{2}$ Assumido a partir de Foucault (2011).
} 
uma relação dialógica. A "ideia é que o texto da pesquisa [seja], em última análise, a narrativa de sua própria experiência" (FOUCAULT, 2011).

Ao assumir uma experimentação de uma escrita a partir das afetações de uma pesquisa, se "aceita a vida e se entrega. De corpo e língua” (ROLNIK, 1989, p. 30). Trata-se de um processo corpóreo em que as intensidades se fazem expressivas quando as paisagens se fazem melódicas e, dessa maneira, emergem ritmos com qualidades próprias em um “território [que,] antes de tudo [é um] lugar de passagem" (DELEUZE; GUATTARI, 1997, p. 132).

Com isso, um ato de criação se inscreve como uma forma outra de sentir e de criar na pesquisa, uma forma que assume um aprendiz sensível, que "procura fazer com que nasça na sensibilidade esta segunda potência que apreende o que só pode ser sentido. É esta a educação dos sentidos" (DELEUZE, 2006, p. 237). Nesse processo, assume-se também uma prática de vida, na busca por produzir diversas formas de sentir e estar no mundo, como possibilidade de abertura e de invenção, com potência para produzir outros modos de existência:

Os indivíduos constroem mundos desde a base dos universos possíveis, um processo estético que cria o novo, que desloca os problemas, desloca os universos de percepções que não compreendem os objetos e não funcionam com as mesmas regras, criam possibilidades inéditas. ${ }^{3}$

Perguntamo-nos: ao assumir uma escrita-corpo, "e o escrever junto ao pesquisar, como línguas são inventadas junto ao pesquisar?” (CLARETO, S.; ROTONDO, 2015, p. 681). Parece-nos que práticas, tanto estéticas como políticas, são construídas a partir da visibilidade e da inteligibilidade dos acontecimentos. E "não [falamos do] que acontece (acidente), [mas] no que acontece, o puro expresso que nos dá o sinal e nos espera” (DELEUZE, 2007, p. 152), um lugar em que a estranheza do mundo se reinstala, instigando-nos à sua problematização. Nesse movimento, buscamos por uma "singularização do acontecimento" sem acompanhar uma linearidade cronológica ou a história de seus feitos. Em tal lógica, o mundo não está para ser compreendido, mas para ser operado, criando outras dinâmicas inventivas, sempre compromissadas com outras formas de vida. Eis sua dimensão ética, que tem como critério "a afirmação de sua potência criadora" (ROLNIK, 1992, p. 8), que produz um lugar da experiência como possibilidade de transformação e de produção de outros modos de vida.

"Quanto de mundo cabe em uma experiência de pesquisar? Inventar mundos: pesquisar. Que mundos são inventados em educação matemática?” (CLARETO, S.; ROTONDO, 2015, p. 673). Produzir atos estéticos que envolvem configurações de experiências outras podem também produzir outras formas de sentir. "Pesquisar com e em e junto a um movimento que instaura modos de estar com a matemática. De estar com a

\footnotetext{
${ }^{3}$ Fala da professora Eugénia Vilela durante a disciplina “Arte, Estética e Política”, ministrada na Universidade
} do Porto em 05 de dezembro de 2017. 
educação. De estar com a pesquisa com e em e junto à educação matemática” (CLARETO, S.; ROTONDO, 2015, p. 673).

Isso tudo implica uma luta: criar possibilidades inéditas de criação, aberturas no e do campo do possível, uma fronteira tomada como um lugar possível de resistência, em que se cria uma relação com o mundo, onde o pulso e a vida dá lugar à luta. Existir é resistir e "resistir é manter-se na fronteira, fazendo do espaço de fronteira uma linha de existência mínima e essencial. Resistir é manter-se num entre-dois cuja tensão insuperável constitui a forma da existência do humano" (VILELA, 2010, p. 202). Um ato de criação que toma a resistência, não para estar contra o poder, senão para resistir a práticas que impõem determinado ritmo "de todas as coisas: de vida de tempo, de pensamento e de discurso" (BARTHES, 2013, p. 68). Para a criação, outros ritmos são necessários. Ritmos que consigam produzir movimentos que criem ressonância e que sejam capazes de impulsionar a própria vida.

"Movimento que agita e esgarça as fronteiras entre matemática e educação e filosofia e história e psicologia e psicanálise e arte e antropologia e música e cinema e escola e cultura e e e...[e que questionem:] Que pesquisa (em educação matemática)?” (CLARETO, S.; ROTONDO, 2015, p. 674).

\section{Una escrita otra...}

Partimos del punto aquel que era nuestro propio vacio y ese punto fue tomado como las hojitas recolectadas por Cortázar. ¿Recuerdan? - "hay tantas cosas que habrán en el aire y que no ven estos ojos, pobres murciélagos de novelas y cines y flores disecadas. Por todos lados habrá lámparas, habrá hojas que no veré".

¿Por qué partimos de las hojas?

La acción de Cortázar volviéndose un antropófago de mundos, coger cada hoja una tras otra, cada hoja un afecto. Instantes producidos que reverberan en el pasado e interrogan el presente, la curiosidad de su perfume - memorias otras producidas. Instantes que convocan a estar abierto al mundo, a la percepción que opera por la sensibilidad en su propio ejercicio empírico, producido entre/con/junto a cuerpos, en las relaciones/encuentros y también por medio del mundo que nos afecta, como nuestra hoja, porque no es solo el objeto, es la memoria que trae consigo aquello que reverbera, que vibra y acciona.

Agarrar el mundo en nuestras manos. Es la invitación que hacemos. Cuerpo siendo afectado por las simplezas, como aquella hoja abandonada en esa calle que quizás no era solo una hoja, sino aquello que le recordaba. El cuerpo aprende siendo afectado, así como nuestra memoria empírica, aquella que "dirige-se a coisas que podem e mesmo devem ser apreendidas de outro modo" (DELEUZE, 2005, p. 138). 
Cuando se está abierto al mundo, a lo sensible, este exige un ejercicio intenso de piel, olor, melodías y demás compases que hacen el cuerpo reverberar. Este ejercicio se refiere a las fuerzas de creación y de resistencia que se movilizan en la subjetividad. Conocer el mundo como forma convoca a la percepción operada por la sensibilidad en su ejercicio empírico; y conocer el mundo como fuerza convoca a la sensación, operada por la sensibilidad en su ejercicio intensivo y engendrado en el encuentro entre cuerpos. Este ejercicio intensivo de lo sensible es llamado por Suely Rolnik como corpo vibrátil ${ }^{4}$.

Sensibilidad-cuerpo, con esa relación el mundo es más allá que una simple forma. $L a$ experiencia sensible parte fundamental de la producción, de los caminos escogidos, el extrañamiento como frontera, como dice Clarice Lispector "e quando estranho a vida aí é que começa a vida" (1994, p. 83). Por eso la importancia de este escrito como proceso creador, escrita-cuerpo y experimentación.

Sabemos que no es fácil desarraigar los hábitos históricos, aquellos que incluso nos pueden llevar a producir nuestros propios dispositivos de control, que se vuelven también dispositivos de control del lenguaje en relación a nuestras prácticas, como leer o escribir. Nuestro trabajo académico no está fuera de eso y esas producciones pueden llevarnos a un conformismo lingüístico.

Poderíamos dizer que o conformismo linguístico está na base de todo conformismo, e que falar como Deus manda, escrever como Deus manda e ler como Deus manda, ao mesmo tempo, é pensar como Deus manda. Também poderíamos dizer que não há revolta intelectual que não seja também, de alguma forma, uma revolta linguística, uma revolta no modo de nos relacionarmos com a linguagem e com o que ela nomeia. Ou seja, que não há modo de pensar de outro modo, que não seja, também, ler de outro modo e escrever de outro modo. (LARROSA, 2016, p. 17).

Así, los convidamos a la abertura, a sentir cada letra y escuchar su música, para hacer de este texto sus propias melodías, y, con eso, ocupar fronteras, crear movimientos y generar con aquello que les inquieta, una escrita rebelde.

\section{Una advertencia}

Lectores, como sabem, los escritores de este texto pueden ir desapareciendo en el momento que intenten encontrarlos. Não compomos este texto para garantir um estado de coisas, o para explicarlas. O que aqui se quer é produzir junto a vocês. Son letras producidas como parte del encantamiento, e por isso não podemos falar de conclusões, ni mucho menos de un punto final. Haverá sim reticências, porque aún habrá mucho por acontecer...

\footnotetext{
${ }^{4}$ Segundo Rolnik (1987), primeiro o olho vibrátil, que faz com que o olho seja tocado pela força do que vê. Segundo, a pele é um tecido vivo e móvel, feito das forças/fluxos que compõem os meios variáveis que habitam a subjetividade. Nesse momento, nosso olho vibrátil capta na pele uma certa inquietação, como se algo estivesse fora do lugar ou de foco.
} 


\section{Operantes}

BARTHES, R. Como viver junto: simulações romanescas de alguns espaços cotidianos: cursos e seminários no Collège de France, 1976-1977. São Paulo: Editora WMF, 2013.

CERTEAU, M. A invenção do cotidiano: 1. Artes de fazer. Petrópolis-RJ: Vozes, 2008.

CLARETO, S.M.; VEIGA, A. L. V. Uma escrita de muitos ou uma escrita em travessia. In: CRISTIANA, C.; RIBETTO, A. Uma outra escrita acadêmica: ensaios, experiências e invenções. Rio de Janeiro: Lamparina, 2016. p.31-47.

CLARETO, S; MIARKA, R. eDucAçÃo Matemática AefeTIvA: nomes e movimentos em avessos. Bolema, v. 29, n. 53, p. 794-808, 2015.

CLARETO, S.; ROTONDO, M. Pesquisar: inventar mundos com Educações Matemáticas. Perspectivas da Educação Matemática, v. 8, n.18, p. 661-687. 2015.

CORAZZA, S; SILVA, T. T. D. Manifesto por um pensamento da diferença em educação. In: CORAZZA, S; SILVA, T. T. D. Composições. Belo Horizonte: Autêntica, 2003. p. 9-17

CORTÁZAR, J. Rayuela. Buenos Aires: Alfaguara, 2015.

CORTÁZAR, J. Un tal Lucas. Buenos Aires: Alfaguara, 2013.

DELEUZE, G Diferença e Repetição. 2. ed. revis. e atual. Tradução L. Orlandi; R. Machado. São Paulo: Graal, 2006.

DELEUZE, G. Proust e os signos. (A. C. Piquet \& R.Machado, Trads). Rio de Janeiro: Forense Universitária. 2007.

DELEUZE, G. Espinosa e o Problema da Expressão. Rio de Janeiro: Editora 34, 2017.

DELEUZE, G. Foucault. Tradução Claudia SantAnna Martin. São Paulo: Editora Brasiliense, 2005.

DELEUZE, G.; GUATTARI, F. Mil Platôs: capitalismo e esquizofrenia. Rio de Janeiro: Editora 34, V1. 1995.

DELEUZE, G; GUATTARI, F. Mil Platôs: capitalismo e esquizofrenia. Tradução Peter Pál Pelbart ; Janice Caiafa. V. 5. Rio de Janeiro: Editora 34, 1997.

LARROSA, J. O ensaio e a escrita acadêmica. In: CRISTIANA, C.; RIBETTO, A. Uma outra escrita acadêmica: ensaios, experiências e invenções. Rio de Janeiro: Lamparina, 2016. p.3147.

LISPECTOR, C. Água viva. Rio de Janeiro: Francisco Alves, 1994.

FOUCAULT, M. Vigiar e Punir. Petrópolis: Vozes, 1996.

FOUCAULT, M. A Escrita de si: o que é um autor? Lisboa: Passagens, 1992.

FOUCAULT, M. A Coragem da verdade: O governo de si e dos outros II: curso no Collège de France (1983-1984). 1. ed. Tradução de Eduardo Brandão. São Paulo: Editora WMF Martins Fontes, 2011. 
GONDIM, D. M.; MIARKA, R. A Constituição de um Plano de Intensidades: aprender e matemática e diferença e escrita-avalanche e... Perspectivas da Educação Matemática, v. 10, n. 22, p. 115-131, 2017.

PASSOS, E; KASTRUP, V. Sobre a validação da pesquisa cartográfica: acesso à experiência, consistência e produção de efeitos. Revista Fractal, v. 25, n. 2, p. 391-414, 2013.

PESSOA, F. Obras em prosa em um volume. Rio de Janeiro: Companhia José Aguilar, 1974.

RANCIÈRE, J. Política da Escrita. Rio de Janeiro: Editora 34, 1995.

ROLNIK, S. Pensamento, corpo e devir: uma perspectiva ético/estético/política no trabalho acadêmico. Cadernos de Subjetividade, v. 1, n. 2, p. 241-251, 1993.

ROLNIK, S. Cartografia sentimental: transformações contemporâneas do desejo. São Paulo: Editora Estação Liberdade, 1989.

ROLNIK, S. Uma insólita viagem à subjetividade fronteiras com a ética e a cultura. In: Cadernos de Subjetividade. Núcleo de Estudos e Pesquisas da Subjetividade, Programa de Estudos Pós Graduados de Psicologia Clínica, PUC/SP. SP, 1997.

ROLNIK, S. À sombra da cidadania: alteridade, homem da ética e reinvenção da democracia. Boletim de Novidades, Pulsional - Centro de Psicanálise, v. 41, p. 33-42. 1992. Disponível em http://www.pucsp.br/nucleodesubjetividade/Textos/SUELY/homemetica.pdf. Acesso em 14 de junho, 2018.

ROLNIK, S. Cartografia, ou de como pensar com o corpo vibrátil. 1987. Disponível em: http://www.pucsp.br/nucleodesubjetividade/Textos/SUELY/pensarvibratil. pdf.

VILELA, E. Silêncios tangíveis. Corpo, resistência e testemunho nos espaços contemporâneos de abandono. Porto: Edições Afrontamento, 2010.

\section{SOBRE OS AUTORES}

PAOLA AMARIS-RUIDIAZ. Formada como Licenciada em Matemática na Universidade Pedagógica e Tecnológica da Colômbia. Mestre (Bolsista CAPES) e doutora (Bolsista CAPES) em Educação Matemática pela Universidade Estadual Paulista (UNESP), Campus Rio Claro, SP. Brasil. Orientada pelo Prf. Dr. Roger Miarka. Membro do Coletivo Cronópios e do grupo de pesquisa I-m@go (Laboratório de Experiência e Cria[@]cão) da Universidade Estadual Paulista (UNESP). Desenvolvendo pesquisas na Educação Matemática junto com a Filosofia da diferença. Encarnada nos pensamentos de Spinoza, Nietzsche, Deleuze e Foucault tem constituído o interesse enquanto movimento de pensamento realizado a partir de noções centrais como: formação de professores, corpo, potência, resistência, experiência e escrita.

ROGER MIARKA. Uma multiplicidade, ainda que na academia seja mais conhecido por ter se formado em Bacharelado e Licenciatura em Matemática pela Universidade Estadual de Londrina, por ser mestre (com bolsa CNPq) e doutor (com bolsa FAPESP) em Educação Matemática pela Universidade Estadual Paulista (UNESP), onde atualmente atua como professor no Departamento de Educação Matemática, e por ter realizado pós-doutorado na Universitat Autónoma de Barcelona. Membro do Coletivo Cronópios e do grupo de pesquisa I-m@go (Laboratório de Experiência e Cria[@]cão), da Universidade Estadual Paulista (UNESP). Busca pensar a Etnomatemática e a Educação Matemática operando obras que 
assumem a diferença como pedra angular, como aquelas escritas por Deleuze e Foucault. Também tem se dedicado a pensar na potência das imagens e de modos outros de escrever na pesquisa. 